\title{
Magnet Shape Influence on the Performance of AFPMM with Demagnetization
}

\author{
Harold Saavedra \\ MCIA Research Group \\ Universitat Politècnica de Catalunya (UPC) \\ Terrassa, Spain \\ harold.saavedra@mcia.upc.edu
}

\author{
Jordi-Roger Riba \\ MCIA Research Group \\ Universitat Politècnica de Catalunya (UPC) \\ Terrassa, Spain \\ riba@ee.upc.edu
}

\author{
Luis Romeral \\ MCIA Research Group \\ Universitat Politècnica de Catalunya (UPC) \\ Terrassa, Spain \\ romeral@eel.upc.edu
}

\begin{abstract}
In this paper the effect of the magnets shape on the AFPMM performance under a demagnetization fault has been analyzed by means of 3D-FEM simulations. Demagnetization faults in permanent magnet synchronous motors (PMSMs) may generate specific fault harmonic frequencies in the stator currents, output torque and the zero-sequence voltage component (ZSVC) spectra the ones can affect motor behavior, and so these parameters have been studied and compared, for each magnet configuration in each condition. These analyses are carried out to find out the more suitable geometry for an operation under healthy and faulty condition.
\end{abstract}

Keywords-component; axial flux motor, harmonic analysis, torque, demagnetization.

\section{INTRODUCTION}

PMSMs are currently being widely applied and are being object of an intense research because they accomplish features well suited for new industrial applications as ships traction, or aerodynamic control, and their compatibility with adjustable speed ac inverter drives. Those features present in PMSMs can be resumed in high-speed operation, precise torque control even at low speed, high power to weight ratio, compactness, and high efficiency [1].

One kind of PMSM is the axial flux permanent magnet machine (AFPMM), which due to its characteristic design, allows electrical motor to fix inside car wheels or hard drives. The disc shape of the active parts of the motor makes it possible to generate diverse and interchangeable designs, i.e. with single or multiple airgaps, with or without slots or even totally ironless armature [2]. The machine dealt with in this work has a single stator and two surface mounted permanent magnets (PM). The stator has a slotted structure with strip wound stator steel. Uniformly distributed back-to-back connected windings are placed into slots [3].

Note that the rotor structure is disc shaped and the rotors carry the axially magnetized magnets which are mounted axially on the inner surfaces of the rotor discs. The windings in radial direction are used for torque production. Taking advantage of a multiple airgap machine configuration, as shown in Fig 1, the end windings can be shortened using the back-to-back connection, which leads to lower copper loss and higher efficiency [4], compared with most conventional configurations.

The operation principle of the AFPMM machine is based on a synchronous machine. The rotor speed depends on the coils excitation frequency. The power switching of the coils excited by electrical current causes the interaction with the magnetic field generated by the magnets, thus producing a torque proportional to the value of current and the air gap flux density. However, the torque ripple level is of concern in lowspeed in-wheel applications. The torque ripple is of special concern at low speed operation, since the system inertia greatly filters out the pulsations of the torque at high speed operation [5].

Demagnetization faults are among the most problematic conditions to deal with in PMSM [6]. The total or partial demagnetization of permanent magnets in a motor, may significantly diminish its torque, thus affecting motor efficiency and performance, even can reduce motor useful life [7]. Although sintered magnets such as $\mathrm{NdFeB}$ are preferred in high power density applications because its magnetic properties, this material also is brittle and easy to crack, therefore a minimal mechanical impact may damage the magnet, causing a partial demagnetization [6].

Demagnetization also can be caused after prolonged expositions of the motor to a sustained short-circuit in stator windings, due to this currents can generates an inverse magnetic field that opposes the magnets remanent flux. Shortcircuits due to inverter or stator-windings faults may also generate fault currents high enough to move the operation point of the rotor magnets into the irreversible demagnetization region [8]. Moreover, if machine works 
under heavy load conditions or harsh transients the armature reaction may demagnetize the permanent magnets [9].

The demagnetization may be complete (all over the magnet) or partial (on a certain region of the magnet). The magnetic-force harmonics induced by demagnetization faults may generate also vibration and noise in the machine.

The purpose of this work is to analyze the influence of the rotor magnets shape on the torque ripple of an AFPM motor under healthy and faulty condition (demagnetization) to be used as the tractive drive of an EV since it is known that magnet modifications greatly influence the AFPMM torque capability and quality. The technique is analyzed in this work because does not increase machine complexity, and gives important data about the machine in harsh regimes, so it is simple and economical from a manufacturing point of view.

\section{THE ANALYZED AFPM MACHINE}

In this work the AFPMM torus-NN configuration has been analyzed because it allows connecting the stator windings in a back-to-back configuration, which allows minimizing the end windings length and therefore copper loss.

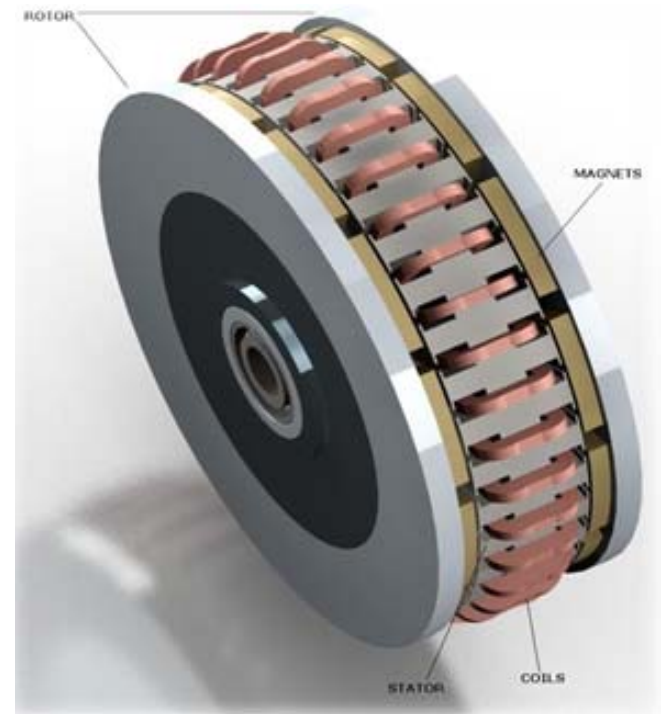

Fig. 1. AFPMM torus-NN analyzed in this work. Each rotor disc contains 12 magnets in a NN configuration. The stator contains 72 slots connected through back-to-back coils. Each phase winding is composed of 12 coils arranged in three parallel branches with four series-connected coils each.

\section{CONSTRUCTIVE FEATURES AND SHAPES OF THE PERMANENT MAGNETS}

This work deals with a $14 \mathrm{~kW}$ AFPM torus machine which was designed at the MCIA Research Laboratory. This machine has two flat rotor discs made of 40CrMnNiMo8-6-4 plastic mold steel with a suitable hardness distribution and wear resistance. The stator, which contains 36 coils (72 slots), is mounted between the two rotor discs. The stator is composed of a solid slotted core of M325-35A, in a donut shape. Each coil has 33 turns of enameled wire with $1.5-\mathrm{mm}^{2}$ cross section, maximum current of $90 \mathrm{~A}, 0.1 \Omega$ resistance and inductance of $575 \mathrm{mH}$. Each rotor includes twelve $\mathrm{NdFeB}$ permanent

magnets, which are arranged in an alternating sequence of poles N-S with an NN topology as shown in Figs. 1 and 2.

The machine parameters are given in Table I. For ease of manufacture, parallel stator slot openings are often employed rather than radial slot openings. When the slot openings are parallel, the ratio of the width of the slot openings to the slotpitch is not constant. As a consequence, the effective cogging torque waveforms at different radii are different.

Five different magnets configurations were chosen [10], as show in Fig 3. All of them were designed to have the same volume of $1.6 \times 10^{-5} \mathrm{~m}^{3}$ and are supposed to be made of the same material, $\mathrm{NdFeB}-35$ with remanence $\mathrm{B}_{\mathrm{r}}=1.23 \mathrm{~T}$.

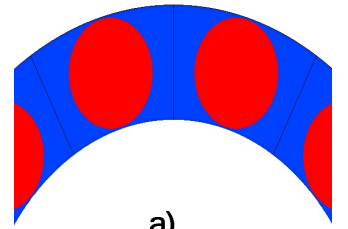

a)

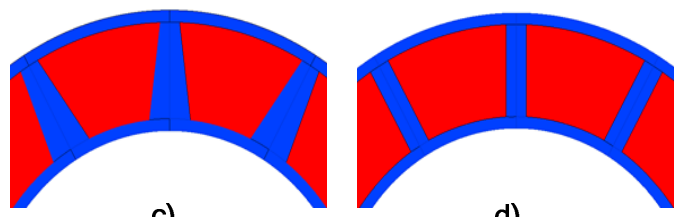

c)

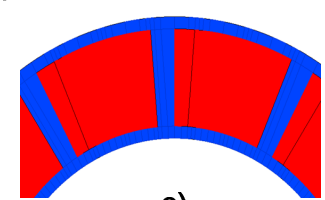

e)

Fig. 2. Analyzed magnets shape. a) Circular magnet. b) Trapezoidal skew. c) Triangular skew. d) Parallel sided. e) Sector or radial magnet shape.

TABLE I. REFERENCE MACHINE CONFIGURATION
\begin{tabular}{|l|c|}
\hline \multicolumn{2}{|c|}{ Torus Characteristics } \\
\hline Rated torque & $170 \mathrm{Nm}$ \\
\hline Rated speed & $800 \mathrm{r} / \mathrm{min}$ \\
\hline Max speed & $1200 \mathrm{r} / \mathrm{min}$ \\
\hline Number of phases & 3 \\
\hline Poles pairs & 6 \\
\hline Disc diameter & $280 \mathrm{~mm}$ \\
\hline Axial length & $120 \mathrm{~mm}$ \\
\hline Airgap length & $1.5 \mathrm{~mm}$ \\
\hline Number of slots per side & 36 \\
\hline Number of coils per phase & 12 \\
\hline
\end{tabular}

TABLE II. MAGNETS PARAMETERS
\begin{tabular}{|l|c|}
\hline Magnets type & NdFeB-35 \\
\hline Max working temperature $\left(\mathrm{T}_{\max }\right)$ & $120^{\circ} \mathrm{C}$ \\
\hline Curie temperature $\left(\mathrm{T}_{\mathrm{C}}\right)$ & $340^{\circ} \mathrm{C}$ \\
\hline Remanence Flux Density $\left(\mathrm{B}_{\mathrm{r}}\right)$ & $1.23[\mathrm{~T}]$ \\
\hline Coercivity $\left(\mathrm{H}_{\mathrm{c}}\right)$ & $890[\mathrm{kA} / \mathrm{m}]$ \\
\hline Thickness & $9.1[\mathrm{~mm}]$ \\
\hline
\end{tabular}




\section{FINITE ELEMENTS MODELING}

As it is well known, although radial-flux machines are often simulated by means of two-dimensional finite elements analysis, an axial flux machine must be modeled by means of three-dimensional finite elements methods (3D-FEM) due to its inherent three-dimensional geometry. All the FEM models analyzed have around 220000 tetrahedral volumetric elements, in order to acquire good results accuracy, as displayed in Fig. 3.

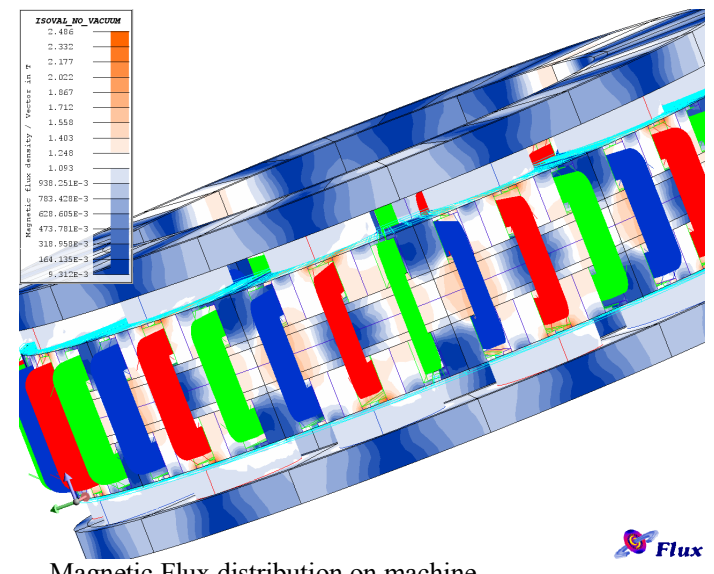

Fig. 3. Magnetic Flux distribution on machine.

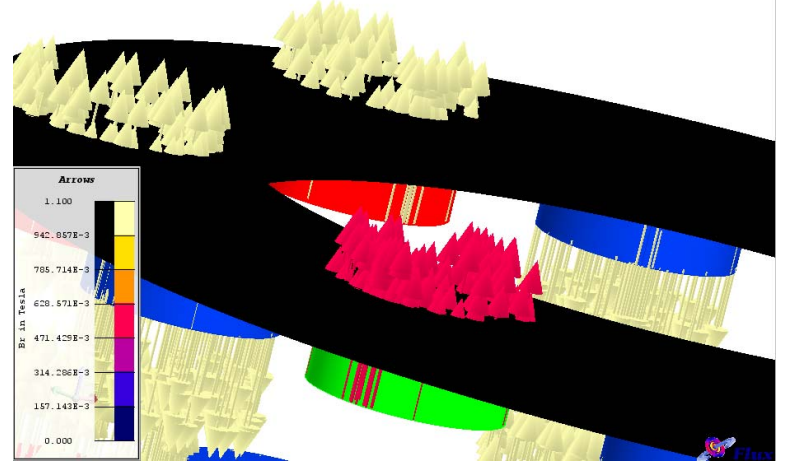

Fig. 4. Demagnetized magnet in green, FEM model.

The AFPM is modeled with three-dimensional finiteelement method. This model includes all geometrical and physical characteristics of the machine components. Fig. 4, shows the precise location of the fault, the arrows indicates the magnetization direction and the color represents the magnetic flux density. Using this accurate modeling makes it possible to obtain demanded signals for a very high precision analysis. Magnetic flux density, back-EMF, magnetic axial force and cogging torque of the motor were simulated using FLUX-3D V10.4.

All the faulty analyzed motors have been simulated by supposing the same demagnetization degree, which correspond to one magnet with half of its normal magnetic remanence $\left(\mathrm{B}_{\text {rdemag }}=1.23 * 0.5[\mathrm{~T}]\right)$

Figs. 7 and 8 show, respectively, the back-EMF waveforms at rated speed and no load conditions and their spectra.

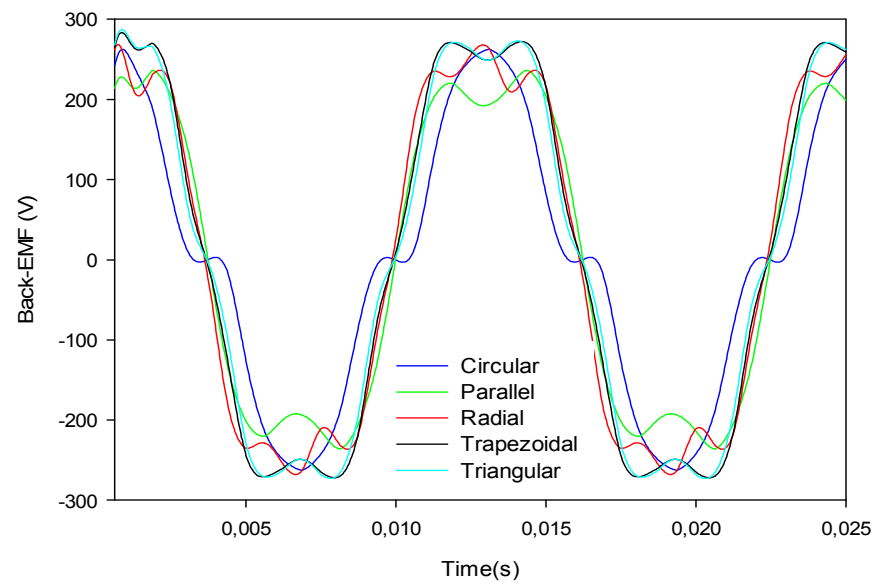

Fig. 5. Back-EMF wave of the analyzed magnets configurations at rated speed under no-load conditions.

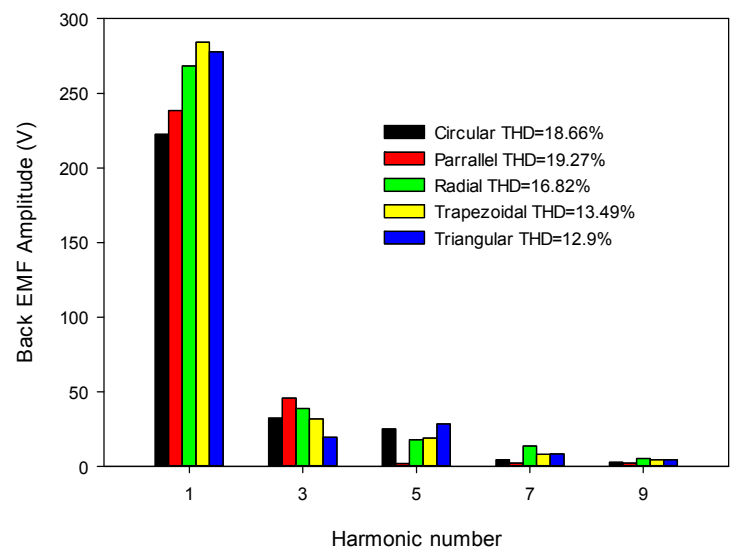

Fig. 6. Back-EMF harmonic distribution of the analyzed magnets configurations at rated speed under no-load and healthy conditions.

Albeit the flux density has an impact on the back-EMF shape, the latter is also greatly influenced by the specific windings configuration of the analyzed machine. As shown in Fig. 6, the triangular and trapezoidal magnets configurations are those with less back-EMF harmonic content. This result suggests that these magnets configurations may improve the torque quality generated by the AFPM, compared with common configurations.

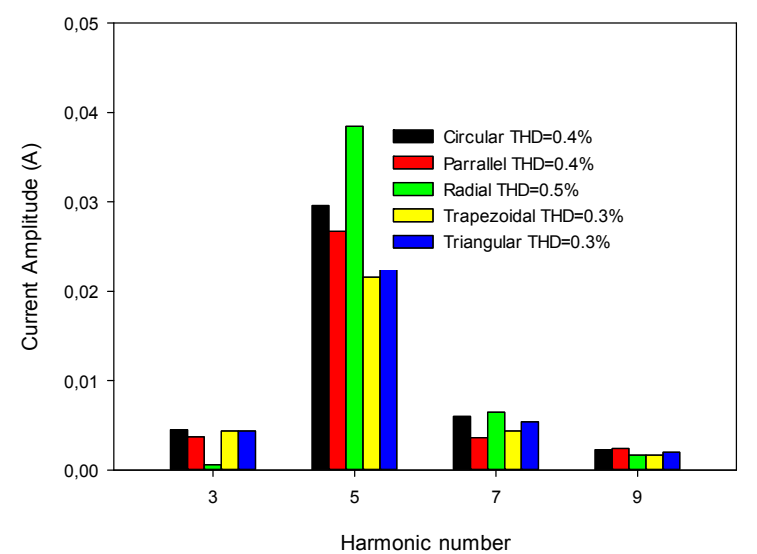

Fig. 7. Currents harmonics healthy condition. 


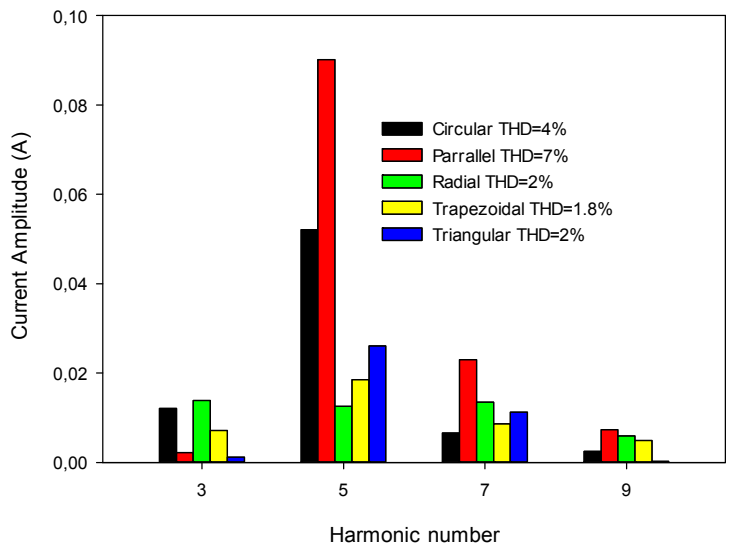

Fig. 8. Currents harmonics with a demagnetization of $50 \%$.

Fig 7 and 8 show the currents spectra in healthy and demagnetization condition, a noticeable reduction of harmonic amplitude is settled which comes mainly from the decrease of averague linkage flux due to demagnetization.

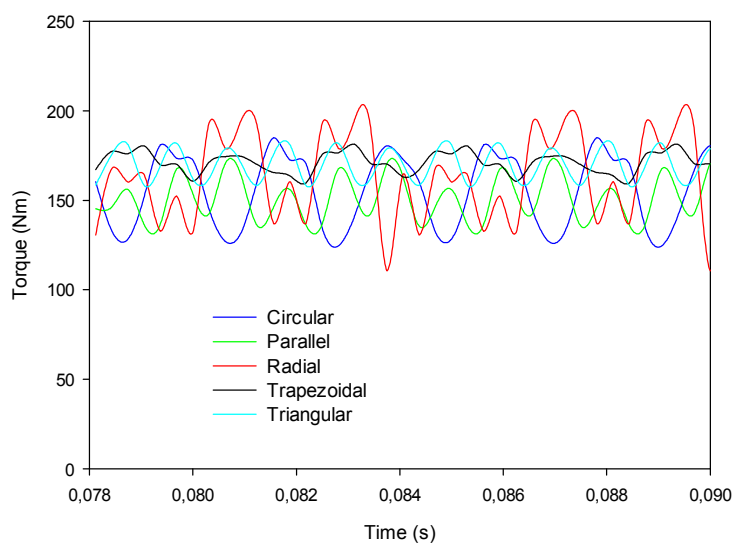

Fig. 9. Torque ripples of the analyzed magnets configurations at rated speed and rated load, healthy condition.

Fig. 9 shows the torque ripples of the different analyzed magnets configurations, which corroborates that the radial magnets configuration is that with higher harmonics content whereas the trapezoidal skew configuration is that with lower content. Even in demagnetized condition, what concludes than a smoother torque can be acomplished easier with a magnet shaped trapezoidally.

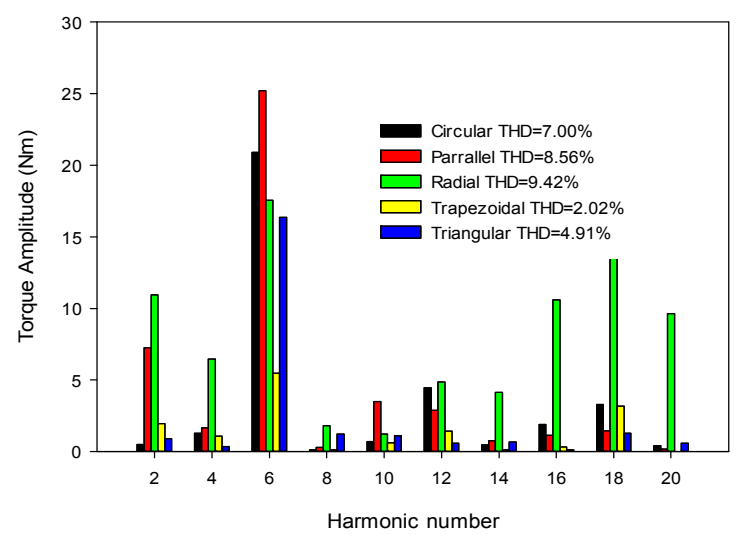

Fig. 10. Torque harmonics distribution of the analyzed magnets configurations. The DC component is not displayed in the figure.

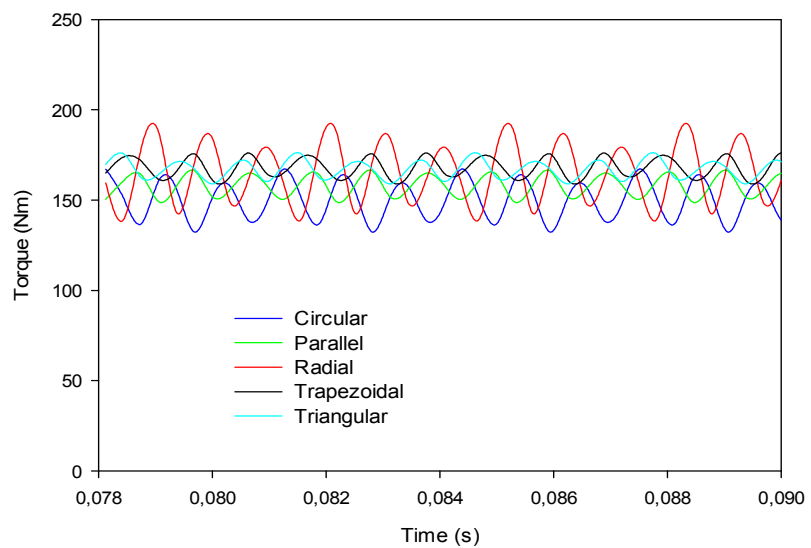

Fig. 11. Torque ripples of the analyzed magnets configurations at rated speed and rated load, faulty conditions (demagnetization of $50 \%$ ).

Table III shows the average torque in healthy and faulty condition, which shows that the configurations with lesser torque ripple (triangular and trapezoidal skew) also lead to higher average torque, even in faulty condition.

TABLE III. AVERAGE TORQUE

\begin{tabular}{|c|c|c|}
\hline Magnets format & $\begin{array}{c}\text { Average torque } \\
\text { healthy }(\mathrm{Nm})\end{array}$ & $\begin{array}{c}\text { Average torque } \\
\text { faulty }(\mathrm{Nm})\end{array}$ \\
\hline Circular & 152 & 150 \\
\hline Parallel & 160 & 158 \\
\hline Radial & 170 & 165 \\
\hline Trapezoidal & 171 & 168 \\
\hline Triangular & 170 & 167 \\
\hline
\end{tabular}

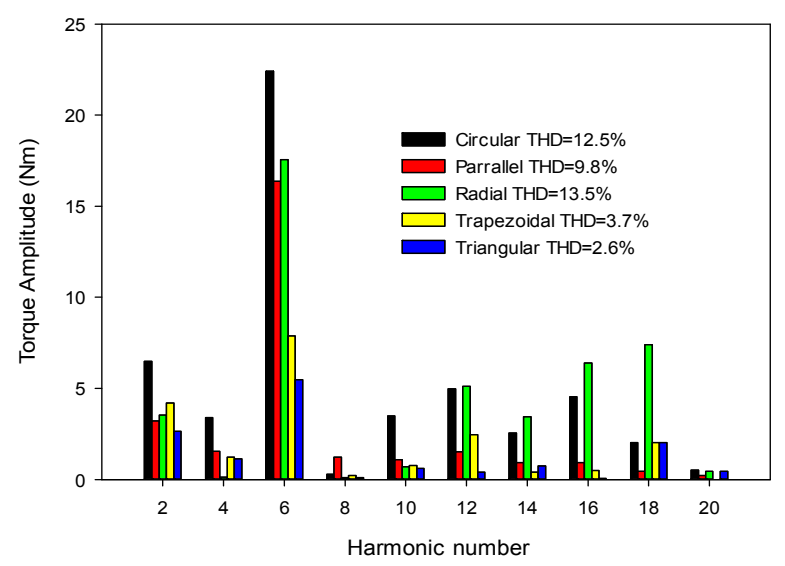

Fig. 12. Torque harmonics distribution of the analyzed magnets configurations, with a demagnetization of $50 \%$

Fig. 11 and 13 shows the torque spectra of the different analyzed magnets configurations, in healthy and faulty condition respectively, although there is a light increase in the total harmonic distortion, the amplitude of most of the harmonics decrease as consequence of demagnetized fault. 


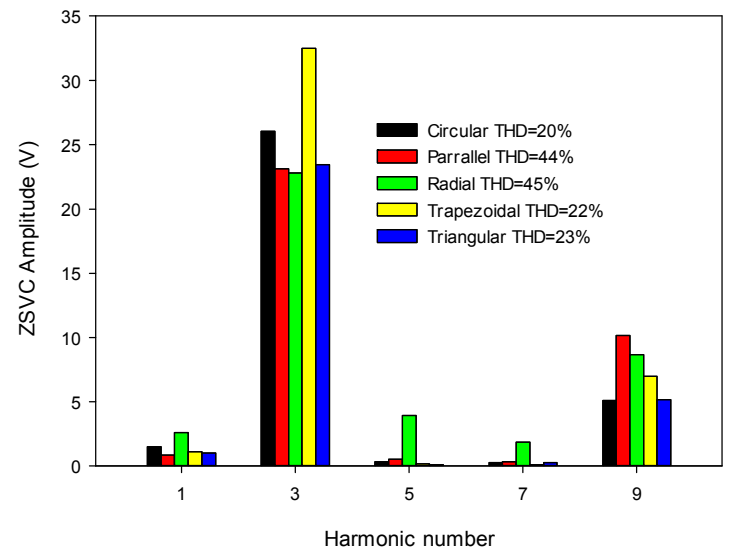

Fig. 13. ZSVC harmonics distribution of the analyzed magnets configurations, healthy conditions.

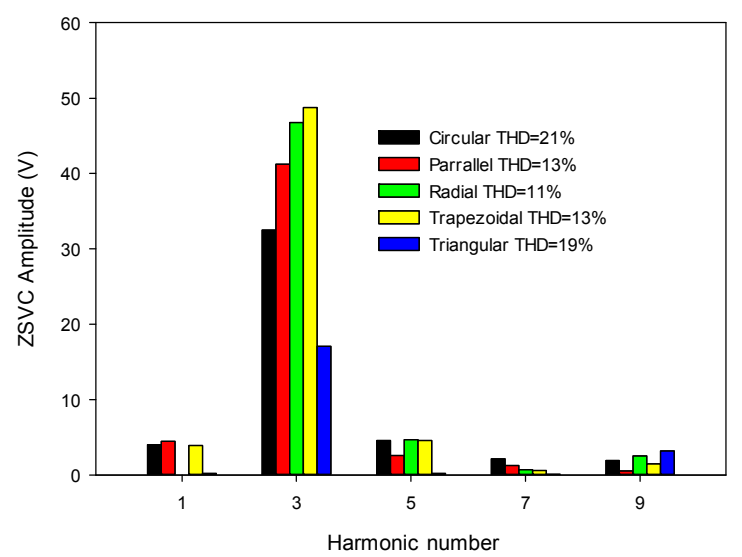

Fig. 14. ZSVC harmonics distribution of the analyzed magnets configurations, with a demagnetization of $50 \%$.

Fig. 14 and 15, show the ZSVC spectra of the different analyzed magnets configurations, although there is a reduction of amplitude of some harmonics, the main harmonic in this case the third increases by almost a $20 \%$ in most of the magnets. As mentioned at [6] the correct measurement of this parameter could aid to detect a partial demagnetization and inform the user about the specific performance of the machine.

\section{CONCLUSIONS}

A simple study has been carried to test the behavior of an AFPM on faulty condition. The main objective was to select the best magnet shape according their performance in healthy and faulty condition in order to take into account in the design of a fault tolerant machine. The results show that trapezoidal and triangular skew magnets shape maintains its low torque ripple in healthy and demagnetization condition.

\section{ACKNOWLEDGEMENT}

This work was supported by the Spanish Ministry of Science and Technology under the TRA2010-21598-C02-01 research project, and by the Catalan Agència de Gestió d'Ajuts Universitaris i de Recerca under the 2009 AGAUR 1235 Research Project.

\section{REFERENCES}

[1] Zhu, Z.Q.; Howe, D.; , "Electrical machines and drives for electric, hybrid, and fuel cell vehicles," Proceedings of the IEEE , vol.95, no.4, pp.746-765, April 2007.

[2] M. Aydin, S Huang, T.A. Lipo, "Axial flux permanent magnet disc machines: a review”, Proc. of EPE PEMC'04,

[3] 2004M. Aydin, S. Huang, T.A. Lipo, "Design and 3D electromagnetic field analysis of non-slotted and slotted TORUS type axial flux surface mounted permanent magnet disc machines," Electric Machines and Drives Conference, 2001. IEMDC 2001. IEEE International, vol., no., pp.645-651, 2001

[4] J. F. Gieras, R. Wang, and M. J. Kamper, Axial Flux Permanent Magnet Brushless Machines, , 2004. : Kluwer York: Academic, 1963, pp. 271-350.

[5] E. Yolacan, E. Ozyurt and M. Aydin, "Magnet shape optimization of a slotted surface-mounted axial gap pm motor for reducing cogging torque", XIX International Conference on Electrical Machines (ICEM), Rome, 2010.

[6] J.-C. Urresty, J.-R. Riba, M. Delgado, and L. Romeral, "Detection of Demagnetization Faults in Surface-Mounted Permanent Magnet Synchronous Motors by means of the Zero-Sequence Voltage Component," IEEE Trans. Energy Convers., vol. 27, no. 1, pp. 42-51, March 2012.

[7] K. C. Kim, S. B. Lim, D. H. Koo, and J. Lee, "The shape optimization of permanent magnet for permanent magnet synchronous motor considering partial demagnetization," IEEE Trans. Magn., vol. 42, no. 10, pp. 3485-3487, Oct. 2006.

[8] M. Delgado, A. Garcia, J. -R. Riba, J. -A. Ortega, "Feature Extraction of Demagnetization Faults in Permanent-Magnet Synchronous Motors Based on Box-Counting Fractal Dimension," IEEE Trans. Ind. Electron., vol. 58, no. 5, pp. 1594-1605, May 2011.

[9] Y. Shenbo and T. Renyuan, "Electromagnetic and mechanical characterizations of noise and vibration in permanent magnet synchronous machines," IEEE Trans. Mag., vol. 42, no. 4, pp. 13351338, Apr. 2006.

[10] M. Aydin, S Huang, T.A. Lipo, "Axial Flux Permanent Magnet Disc Machines: a review", in Conf. Record of SPEEDAM, Capri, Italy, May 2004, pp. 61-71. 